\title{
Recent advances in the use of Langmuir monolayers as cell membrane models
}

\author{
Andressa Ribeiro Pereira ${ }^{1+}{ }^{\circ}$, Osvaldo Novais de Oliveira Junior ${ }^{1}{ }^{\circ}$ \\ 1. University of São Paulo, São Carlos Institute of Physics, São Carlos, Brazil.
}

+Corresponding author: Andressa Ribeiro Pereira, Phone: +55 11 98229-0202, Email address: andressa.arp@gmail.com

\section{ARTICLE INFO}

Article history:

Received: July 10, 2020

Accepted: September 07, 2020

Published: April xx, 2021

\section{Keywords}

1. Langmuir monolayers

2. cell membrane models

3. chitosans

4. pharmaceutical drugs

\begin{abstract}
Understanding the role of biomolecules in cells at the molecular level has been the trade of Prof. Marcio Francisco Colombo and Prof. João Ruggiero Neto in their carriers, which is why it was found appropriate to address the use of Langmuir monolayers as cell membrane models in this special issue. In the review paper, we elaborate upon the reasons why Langmuir monolayers are good models with the possible control of membrane composition and molecular packing. After describing several experimental methods to characterize the Langmuir monolayers, we discuss selected results from the last five years where monolayers were made to interact with pharmaceutical drugs, emerging pollutants and other biologically-relevant molecules. The challenges to take the field forward are also commented upon.
\end{abstract}
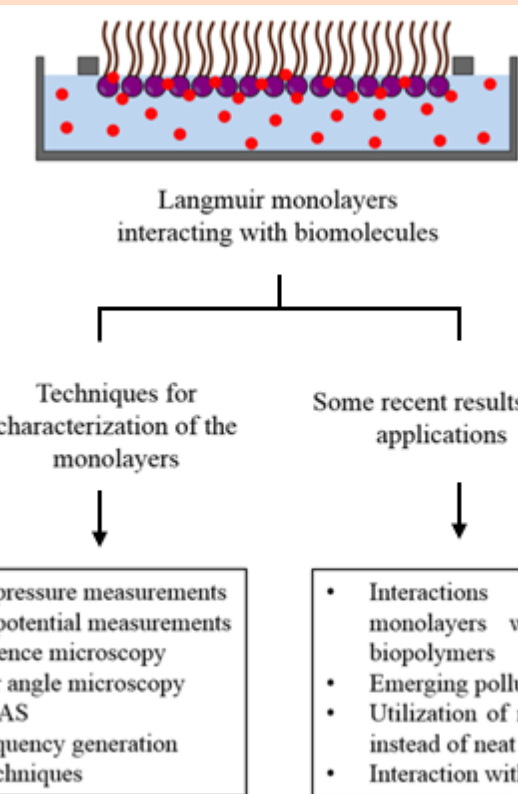

Some recent results and applications

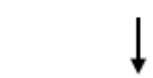




\section{Introduction}

Langmuir monolayers ${ }^{1-3}$ have long been used as simplified membrane models as they mimic half of the cell membranes that are formed by a fluid lipid bilayer containing proteins and polysaccharides ${ }^{4,5}$. The reason why membrane models are employed is the difficulty to characterize the cells directly, particularly if molecular-level information is required. Since the seminal works by RAYLEIGH ${ }^{6}$, Langmuir ${ }^{7}$ and Nandi and Vollhardt ${ }^{8}$, monolayers have been utilized for in situ characterization of surfactant molecules at the airliquid interface and in the formation of LangmuirBlodgett (LB) films ${ }^{9,10}$. Because lateral organization is important and there are specific lipid functions in biomembranes, the Langmuir monolayer model is advantageous, as the area per molecule and lipid composition are controlled precisely. Furthermore, with monolayers, one may investigate biomoleculemembrane interactions by modifying and controlling the lipid charge and structure, and subphase conditions, such as $\mathrm{pH}$ and concentration of the biologicallyrelevant molecules ${ }^{11,12}$.

Since the 1990s, novel in situ methods have been made available to study liquid interfaces with microscopic and molecular resolution, as described in recent reviews ${ }^{1-3,13}$. In Section 2 in this review paper, we describe several methods to characterize Langmuir monolayers, while selected results from the last five years with monolayers used as membrane models are discussed in Section 3. These results refer to a few topics that have gained prominence, viz. interaction with pharmaceutical drugs and emerging pollutants, enzyme activity, use of lipid mixtures to better mimic a real membrane and interaction with chitosans.

\section{Methodology}

Langmuir monolayers are obtained with instruments referred to as Langmuir troughs, with which a solution of an amphiphilic material is spread at the air-water interface. These Langmuir troughs are made of inert materials, usually Teflon, and contain movable barriers, one pressure sensor and one dipper. For monolayer formation, a small volume of a diluted solution of the selected compound in a volatile organic solvent (usually chloroform) is spread over the water surface. The barriers allow the area occupied to be varied and the dipper permits immersion of substrates for LB film deposition. The pressure sensor measures the surface pressure $(\pi)$, normally with the Wilhelmy method $^{14}$. After solvent evaporation, the barriers compress the molecules at a constant rate, which makes them oriented in relation to the water surface, with the hydrophobic portions facing air and hydrophilic portions in contact with the water. When the film is closely packed and continues to be compressed, collapse occurs with disordered layers being formed ${ }^{15}$. There are several methods to study the properties of a Langmuir monolayer. For various spectroscopic and microscopy methods and other in situ characterization techniques, the Langmuir trough is installed to give access to the measuring systems. In this review paper, we shall introduce methods which have been employed in Brazil or by Brazilian researchers in collaboration with international partners.

\subsection{Surface pressure measurements}

The most popular way to characterize Langmuir monolayers is to obtain the surface pressure-area $(\pi-\mathrm{A})$ isotherm ${ }^{3}$. From the isotherms, one may determine the molecular area, monolayer phases, collapse behavior, compressibility and interaction with species in the subphase. The measurement is usually done in a pseudo-equilibrium condition, with a continuous compression of the monolayer while the surface pressure is monitored. Surface pressure is measured by either of two main methods: the Langmuir balance, which is a differential measurement, and the Wilhelmy plate, an absolute method that involves the forces acting on the plate (made of platinum or filter paper) partially immersed in the subphase ${ }^{3}$. The surface pressure $(\pi)$ is defined as the difference between the surface tension of one subphase in absence of the compound $\left(\gamma_{0}\right)$ and in the monolayer presence $(\gamma)$, as in Eq. 1:

$\pi=\gamma_{o}-\gamma$

The minimum pressure is zero and the maximum is around $73 \mathrm{mN} \mathrm{m}^{-1}$ (at $25^{\circ} \mathrm{C}$ ), which corresponds to the surface tension of pure water if the monolayer is stable $^{14}$. The factors that affect the shape of surfacepressure isotherms include experimental conditions and chemical modification of the molecule's structures, such as their polarity, size and shape ${ }^{16}$. The analysis of surface pressure isotherms yields information on the collapse pressure and the compressibility modulus $\left(\mathrm{C}_{S}{ }^{-1}\right)^{17}$. The latter allows one to characterize the state of the monolayers and the phase transitions, and may be calculated using Eq. 2:

$C_{S}^{-1}=-A \frac{d \pi}{d A}$ 
where A corresponds to the mean molecular area and $\pi$ is the surface pressure.

\subsection{Surface potential measurements}

The surface potential $(\Delta \mathrm{V})$ technique has been utilized over decades with Langmuir monolayers. It is defined as the potential difference between an aqueous surface in the presence of a Langmuir monolayer and a surface without the monolayer. This measurement provides information about the dipole moments of the film-forming materials, in addition to changes in orientation of water molecules in the subphase and of the double-layer formed in ionized monolayers between the electrolytic subphase and the headgroups ${ }^{3}$. The measurement of surface potential is usually made with a Kelvin probe in a vibrating capacitor scheme. The surface potential changes when the film is compressed, owing to reorientation of the head or tail groups. Theoretical models have been used to relate the measured potentials with the dipole moments of the molecules. In one of these models ${ }^{18}$, the monolayer was considered as a three-layer capacitor, each layer with its "effective" dipole moment and local dielectric constant. As the interactions between the molecules are weak for large areas per molecule, the surface potential of the monolayer is zero. During monolayer compression, there is a critical area in which the potential is no longer null and increases rapidly with the decrease in area per molecule. It is worth mentioning that the surface potential is more sensitive to the organization of the Langmuir monolayers than the surface pressure ${ }^{14}$.

\subsection{Fluorescence microscopy}

Fluorescence microscopy is used to obtain structural information and study the dynamics of possible chemical and structural changes in Langmuir monolayers. The technique requires that molecules in the monolayer contain dyes or chromophores ${ }^{14}$, with an incident light (from the air or from the water) exciting the monolayer material or incorporated dyes. As the solubility of the fluorescent probe depends on the monolayer state, a contrast is originated upon changing these states ${ }^{3}$. Therefore, with fluorescence microscopy one may inspect the molecular aggregates and domains at different film compression stages. The analysis of fluorescence microscopy data may be difficult due to the possible segregation of probe molecules, which can form separate monolayer phases ${ }^{19}$. This occurs because a fluorescent amphiphilic molecule can be added to the monolayer. Since this probe could act as an impurity in the monolayer, its solubility can vary in the coexisting phases. Also, significant are the possible photochemical transformations in the fluorescent probes, which should be accounted for ${ }^{20,21}$.

\subsection{Brewster angle microscopy}

Brewster angle microscopy (BAM) was reported in 1991, independently, by two groups: Hénon and Meunier from France and Hönig and Möbius from Germany ${ }^{21,22}$. Similarly to fluorescence microscopy, BAM allows the observation of the mesoscopic morphology and ordering of condensed phase domains $^{23}$. One of the main advantages of BAM compared to fluorescence microscopy is that it does not require external probes, which means that the monolayers may be visualized on a mesoscopic scale without external interference ${ }^{24}$. Brewster angle microscopy also provides information about monolayer phases, packing of the molecules, phase transitions and chemical modifications ${ }^{25}$. The principle of BAM is based on reflection spectroscopy. The plane interface reflectivity between two media of refractive index $\left(\mathrm{n}_{1}\right.$ and $\mathrm{n}_{2}$ ) depends on the polarization $(\alpha)$ of the incident light and on the angle of this incidence $(\theta)$. For $p$ polarization (electric field in the plane of incidence) and considering a Fresnel interface, the reflectivity vanishes at the Brewster angle $\left(\theta_{\mathrm{B}}\right)$, as indicated in Eq. 3:

$\tan \left[\theta_{B}\right]=n_{2} / n_{1}$

Condensed monolayer phases affect the refractive index with measurable changes in reflectivity ${ }^{24}$. Three origins may be identified for the reflectivity: the thickness and roughness of the interface and the anisotropy of the monolayer ${ }^{21}$. For the air-water interface, the Brewster angle is $53^{\circ}$ for $p$ polarization light. When a monolayer is introduced, a new interface is formed and $\alpha$ is changed. Thus, the light is reflected and can be observed with a microscope, which allows for monolayer visualization ${ }^{26,27}$.

\subsection{Polarization modulation infrared reflection absorption spectroscopy (PM-IRRAS)}

Spectroscopy in the infrared region allows one to investigate vibration modes of the chemical bonds. For Langmuir monolayers, it has become frequent to employ polarization-modulated infrared reflection absorption spectroscopy (PM-IRRAS). This method is 
sensitive to the component of the perpendicular dipole moment in relation to the substrate ${ }^{14}$, thus yielding information on the orientation of film-forming molecules ${ }^{28,29}$. The importance of polarization modulation is related to the minimization of the absorption of the water vapor and making PM-IRRAS surface specific ${ }^{30}$. Polarization modulated infrared reflection absorption spectroscopy was developed around 1990 and has been utilized with metallic substrates as well as in Langmuir monolayers. It combines Fourier transform and mid-infrared reflection spectroscopy with polarization modulation of the incident beam with two-channel electronic and mathematical processing of the detected signal ${ }^{31}$. By alternating $s$ - and $p$-polarizations in the impinging light at a high frequency using a photoelastic modulator, the reflectivity of both polarizations are detected. The difference between them yields surface specific information while their sum serves as reference. The ratio between the difference and sum is the PM-IRRAS signal, in which the gas phase absorbance is compensated $^{32}$. With PM-IRRAS one may distinguish between in-plane and out-of-plane vibrations. For instance, positive bands correspond to the vibrations parallel to the water surface, while negative bands are due to vibration modes normal to the water surface ${ }^{3}$.

\subsection{Sum-frequency generation}

Sum-frequency generation spectroscopy (SFG) has been developed as a surface-specific technique for interfaces and surfaces ${ }^{33,34}$. As a second-order nonlinear optical process, SFG is forbidden under the electric-dipole approximation in media with centrosymmetry, and a signal is only measured when the inversion symmetry is broken ${ }^{35,36}$. Sum-frequency generation spectroscopy utilizes different input/output polarization combinations, which provide a great deal of structural information ${ }^{37}$, including for different Langmuir monolayer phases. A unique feature of SFG is the possibility to investigate the interfacial water layers, which can be affected by changes in ion concentration and $\mathrm{pH}^{38,39}$. In $\mathrm{SFG}$, two input laser beams overlap to generate an output at a frequency which is the sum of the incoming frequencies. One frequency is visible while the infrared beam is tunable. When this infrared frequency approaches a surface resonance, the SFG output is enhanced and a spectrum of the surface or the interface is obtained ${ }^{40}$, in some cases identifying the chemical groups ${ }^{41}$. The vibrational spectrum is thus obtained with the detection of the light with summed frequencies ${ }^{42}$.
In general, infrared spectroscopy has enough sensitivity to detect a surface monolayer. However, the spectrum is usually complicated and the information about the conformation of the monolayer chain is indirect. In SFG, on the other hand, the spectra of the hydrocarbon chains are simplified by the intrinsic selection rules and they are sensitive to chain conformation, which means that they can be used to provide qualitative information about chain conformation ${ }^{40}$. The selection rules for sum frequency involve the asymmetric environment, and the asymmetry must be satisfied in molecular and macroscopic levels. On a macroscopic scale, the sum frequency is inactive, because isotropic distribution of molecules in the bulk phase is centrosymmetric. For interfacial molecules to be active, a net polar orientation is necessary, since no SFG signal is observed when the surface structure is completely disordered $^{42,43}$.

\subsection{X-ray techniques}

The structure of Langmuir monolayers started to be investigated in detail in the 1980s when synchrotron light sources became available. With grazing incidence X-ray diffraction (GIXD) measurements, it was possible to determine the in-plane structures for the first time, including tilt directions and tilt angles with Angstrom resolution ${ }^{44}$. This technique is based on the total reflection phenomenon, in which the electromagnetic wave propagates at a critical angle along the boundary between two media and is totally reflected from the medium with the lower refractive index. The GIXD is highly surface sensitive because a monochromatic X-ray beam with a well-defined wavelength is used to focus the water surface at an angle $\alpha_{i}$ (a value below the critical angle $\alpha_{c}$ of total external reflection). The evanescent wave propagates along a top layer of only $8 \mathrm{~nm}$. For a crystalline monolayer, the evanescent wave may be scattered from the lattice planes as in a Bragg scattering ${ }^{45}$. The types of information that may be obtained with GIXD include molecular organization in terms of unit cell dimensions and orientation of the molecules in relation to the interface.

In addition to GIXD, two other techniques have been important for the study of Langmuir monolayers: specular X-ray reflectivity (XR) and total reflection Xray fluorescence (TRXF). With $\mathrm{XR}$, one may probe non-structured liquid monolayers, which is not possible with GIXD. From XR experiments, the vertical structure of the monolayer may be determined, regardless of the phase state. The incident angle $\alpha_{i}$ can 
vary from 0.01 to $0.8 \AA^{-1}$ of the vertical scattering vector component (Eq. 4).

$Q_{z}=(4 \pi / \lambda) \sin \left(\alpha_{f}\right)$

The background scattering from the subphase is measured at $2 \theta=0.7^{\circ}$ and subtracted from the specular signal measured at $2 \theta=0^{45}$.

Total reflection X-ray fluorescence is a simple method to characterize quantitatively the monolayers ${ }^{46}$. For the coupling between electron and X-ray to be efficient, the gap between the energy of the X-ray beam and the edge energy should not be too large, which means that the X-ray energy depends on the type of element to be detected. However, in some cases, the fluorescence process is inefficient and the radiation is much weaker than the primary beam. Hence, light elements cannot be detected because of instrumental limitations and low X-ray fluorescence yields. In TRXF, the measurement does not depend on the structure and monolayer composition, it depends on the experimental conditions, the fluorescence yield for a line and the X-ray absorbance of an element. The fluorescence intensity $\left(\mathrm{I}_{\mathrm{i}}^{\mathrm{f}}\right)$ of an element $I$ with a concentration profile $\mathrm{c}_{\mathrm{i}}(\mathrm{z})$ (in the directional normal to the interface) is given in Eq. 5:

$I_{i}^{f}=b_{i} \int I_{e x}(z) c_{i}(z) d z$

where $I_{e x}(z)$ corresponds to the exciting X-ray intensity at a distance $\mathrm{z}$ from the surface and $b_{i}$ is a constant $^{45}$.

\section{Summary of recent results}

The use of Langmuir monolayers as cell membrane models has continued as a popular topic, with more than 500 papers in indexed journals (in the Web of Science in July, 2020) over the last five years. For this review paper, we have chosen a few topics associated with drugs and biopolymers, which interactions with cell membranes are essential for their physiological action $^{47}$.

The first topic is associated with pharmaceutical drugs which physiological action may be correlated with the ways they interact with cell membranes. Rodrigues et al ${ }^{48}$ investigated bacitracin, a drug used for treating minor wounds. Bacitracin is able to disrupt membrane models representing gram-positive and gram-negative bacteria. They observed that bacitracin is incorporated in 1,2-dipalmitoyl-sn-glycero-3phospho-L-choline (DPPC), 1,2-dipalmitoyl-snglycero-3-phospho-(1'-rac-glycerol) (DPPG) and 1,2-
dipalmitoyl-sn-glycero-3-phospho-L-serine

(DPPS)

monolayers, and affects the monolayer morphology, as they showed in BAM images. The effects from bacitracin depended on the nature and microenvironment of the monolayer, as well as on the lipid polar head. For DPPC and DPPG, bacitracin expands the lipid monolayer, while for DPPS the drug condenses it. The observation that bacitracin interacted with the phospholipid monolayers at a surface pressure typical of a real membrane model (i.e. $30-35 \mathrm{mN} / \mathrm{m}$ ) was of biological relevance ${ }^{48}$.

Węder et al. ${ }^{49}$ studied 2-hydroxyoleic acid (2OHOA or Minerval) and its interaction with different membrane components, such as cholesterol, sphingomyelin and phosphatidylcholine ${ }^{50}$. They observed that the interactions between the lipids and the 2OHOA in the monolayer are more favorable when the monolayer is more fluid. The effects of 2OHOA depended on the condensation of monolayers mimicking lipid rafts; the ability of $2 \mathrm{OHOA}$ to destabilize and modify the morphology of the monolayers was suggested to be linked to its activity. Some classes of peptides are promising for killing bacteria, especially as they can disrupt bacteria membrane. This has motivated a number of studies with Langmuir monolayers ${ }^{51}$, including those from Prof. João Ruggiero ${ }^{52}$. In the latter study, the interaction of peptides was studied with Langmuir monolayers of DPPC, which was used to verify the influence of a peptide on lipid packing during the LELC coexistence plateau. Their results permitted to confirm that the subphase $\mathrm{pH}$ is an important parameter which modulates the peptide surface activity. Also relevant was the conclusion that the mutual lateral interaction could stabilize the peptides in the hydrophobic region of the membrane.

The importance of immobilizing enzymes in Langmuir and Langmuir-Blodgett films arises from the possible monitoring of catalytic activity at the molecular level ${ }^{13,53}$. Also significant is the finding that the environment provided by the lipid-enzyme architecture could conserve the catalytic activity for a long time ${ }^{54,55}$, which is interesting for biosensors. Rocha Junior and Caseli ${ }^{56}$ studied the surface activity of the enzyme asparaginase at the air-water interface. Asparaginase is responsible for catalyzing the hydrolysis of asparagine to aspartic acid and ammonia and serves as an antitumorigenic agent ${ }^{57}$. They detected the formation of mixed asparaginase-DPPC monolayers using surface pressure and surface potential measurements and vibrational spectroscopy. Asparaginase decreased the lipid surface elasticity, increased the surface potential and condensed the 
monolayer. When asparaginase was immobilized in phospholipid LB films, its activity was better preserved than in a homogeneous medium ${ }^{56}$.

An increased use of emerging pollutants with Langmuir monolayers has been noted for two main reasons. These pollutants have attracted considerable attention and their study in in vivo systems is difficult ${ }^{58}$. Alessio et al. investigated the interactions of the pollutants amoxicillin (AMX) and methylene blue (MB) with a simple membrane model consisting of DPPC monolayers ${ }^{59}$. Amoxicillin is an antibiotic of the penicillin family used to treat bacteria-related infections, and $\mathrm{MB}$ is a phenothiazine derivative used as a medicine ${ }^{60}$, among other applications ${ }^{61}$. Amoxicillin and MB shifted the surface pressure of DPPC monolayers to larger areas and made these monolayers more compressible, as observed in Fig. 1. Even more important was the observation that a stronger effect occurred when the two pollutants were mixed, which was corroborated with PM-IRRAS data. This synergistic effect is in line with the problems reported about cooperative action of pollutants effects $^{59}$. a)

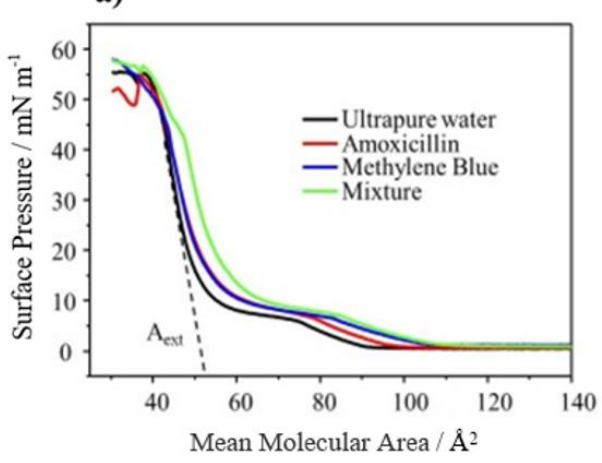

b)

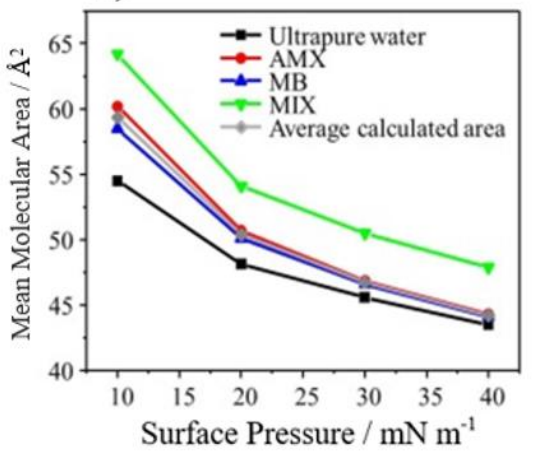

c)

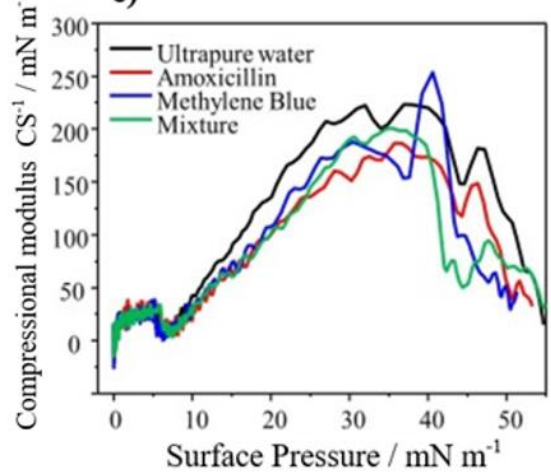

Figure 1. (a) Surface pressure isotherms of DPPC for $10^{-4} \mathrm{~mol} / \mathrm{L}$ subphases with AMX, MB and the mixture at $23{ }^{\circ} \mathrm{C}$. (b) Modifications of the area induced by the subphases of AMX, MB and the mixture. (c) Compressional modulus versus surface pressure for DPPC monolayers obtained from the $\pi$ - $A$ isotherms. Reproduced from Maximino et al. ${ }^{59}$ with Elsevier permission.

Another work related to pollutants by Węder et al. ${ }^{62}$ involved the persistent organic pollutants polycyclic aromatic hydrocarbons (PAHs) ${ }^{63}$ that can easily migrate in the environment. One way to eliminate PAHs is through bioremediation by using soil decomposer consortia in bacterial species capable of PAHs degradation ${ }^{64,65}$. However, the surface of the soil bacteria is hydrophilic, while PAHs are hydrophobic, so the direct contact between them is very limited. With this problem in mind, the authors proposed to study Langmuir monolayers from bacterial phospholipids as model membranes, as the studies in the literature are predominantly based on phosphatidylcholines (PC) ${ }^{66}$, which do not occur in this type of membrane. The lipid mixtures they used contained cardiolipin, phosphatidylglycerol and phosphatidyl ethanolamine. Six PAH molecules were employed, which showed different behaviors in contact with the monolayers. The results do not depend on the kind of the polar headgroup of the lipids. Polycyclic aromatic hydrocarbon molecules do not have any polar groups and, therefore, they are incorporated between the hydrophobic chains of the phospholipid and interact with them, avoiding the hydrated regions of the monolayers. Based on the results for the various monolayers, Węder et al. ${ }^{62}$ suggested that the toxicity of PAH molecules is directly related to their interactions with the membrane phospholipids.

One of the major challenges in the use of Langmuir monolayers as cell membrane models is to mimic the rich variety of membrane composition. For decades, most studies employed only neat phospholipids in the monolayers in order to make it simple. In recent years, attempts have been made to better mimic the membrane composition by using mixtures of lipids. Herein, we mention some contributions from the last four years in this topic. Sun et al. ${ }^{67}$ used the mixtures of POPC/DPPC and POPC/DPPC/Chol (POPC is 1palmitoyl-2-oleoyl-sn-glycero-3-phosphocholine and Chol is cholesterol) to investigate interactions with Lycium barbarum polysaccharides (LBP), natural biopolymers used in medicine and in the food industry ${ }^{68}$. A fewer number of LBP molecules 
interacted with POPC/DPPC/Chol monolayers in comparison to POPC/DPPC monolayers, and $\mathrm{CS}^{-1}{ }_{\max }$ was higher for the ternary mixture. These results indicated that the presence of cholesterol led to a more rigid, more stable membrane at the air-water interface. They were interpreted as considering that cholesterol protected the cell membrane from the effects of LBP. Another example of lipid mixtures in Langmuir monolayers included different proportions of Chol and sphingomyelin (SM) in a study of effects from the antimalarial drug cyclosporine $\mathrm{A}^{69}$. Cholesterol is known to affect membrane fluidity ${ }^{70,71}$ and forms the so-called lipid rafts along with $\mathrm{SM}^{72,73}$. Wnętrzak et al. ${ }^{69}$ observed that cyclosporine A was distributed on the monolayers in different ways, depending on the CholSM proportion. Cyclosporine A induces modifications in SM-Chol model membranes, especially in their mechanical properties. These modifications could affect the antimalarial activity of cyclosporine A, since this drug may disorganize SM-rich domains, which destabilizes the vacuolar membrane, preventing the development of parasites.

As already mentioned, Chol affects the conformational order and membrane permeability, thus regulating the lateral organization of membrane components ${ }^{13,70,72,74}$. This has been studied in detail on aminophospholipid membranes ${ }^{75}$. The isotherms and compressibility modulus depend on the Chol concentration, and the same applies to the molecular organization inferred from X-ray reflectivity measurements (XRR).

The third type of representative study of cell membrane models involves chitosans, which applications in medicine depend on their interactions with biomembranes. Owing to their biocompatibility and biodegradability, chitosans have been used in drug delivery ${ }^{76}$ and as bactericidal agents ${ }^{77}$. Pavinatto et al. ${ }^{78}$ investigated the interaction between two samples of chitosan with different molecular weights and zwitterionic (DPPC) and negatively charged (DPPG) phospholipids. The action of chitosan depends on three factors: degree of acetylation ${ }^{79,80}$, molecular weight ${ }^{81}$ and functionalization ${ }^{82}$. The goal of this study was to show that smaller chitosan chains are more capable of penetrating into the membranes ${ }^{83}$. Both chitosans expanded the DPPC and DPPG monolayers and reduced their compressibility modulus, but the effects were more pronounced for the low molecular weight sample, as shown in Fig. 2. Furthermore, interaction was stronger with DPPG, owing to its negative charge. The reason why chitosans with lower molecular weight had more access to the monolayer was identified by dynamic light scattering measurements with the chitosan solutions. Larger aggregates were observed for the high molecular weight chitosan, which hampered the access to the phospholipid hydrophobic tails $^{78}$.
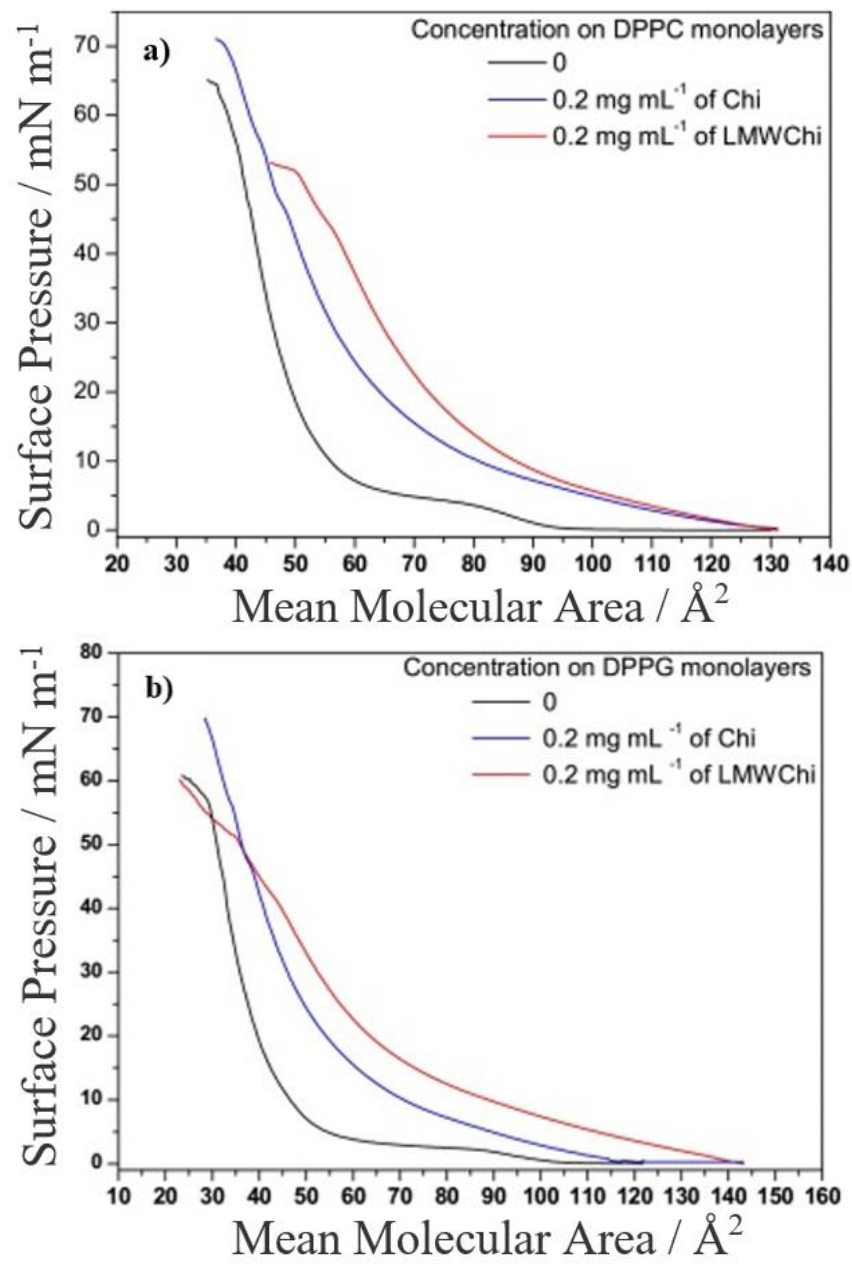

Figure 2. Surface pressure-area isotherms for (a) DPPC and (b) DPPG monolayers. Subphase: TS buffer pH 3.0 and $0.2 \mathrm{mg} \mathrm{mL}^{-1}$ commercial chitosan (Chi) and lower molecular weight chitosan (LMWChi). Reproduced from Pavinatto et al. ${ }^{78}$ with Elsevier permission.

Until recently, all the experiments with Langmuir monolayers were made with chitosans that were only soluble at acidic subphases. This has changed with the development of a novel strategy to produce chitosans soluble at a wide $\mathrm{pH}$ range with controllable degree of acetylation $^{84}$. A chitosan with $35 \%$ acetylation degree (Ch35\%) was made to interact with Langmuir monolayers of equimolar mixtures of (SM/DPPC/Chol) to mimic lipid rafts in cell membranes ${ }^{85}$. The most important observation was that interaction with such lipid rafts occurred at chitosan concentrations much 
lower than reported in the literature, as shown in Fig. 3 for a subphase of phosphate buffer saline (PBS) solution. In fact, interaction with the SM/DPPC/Chol was always stronger than for the pure DPPC, and this applied not only to the high molecular weight Ch35\%, but also for other types of chitosan. It is also worth noting that the interactions with SM/DPPC/Chol monolayers are even more pronounced for acidic subphases.

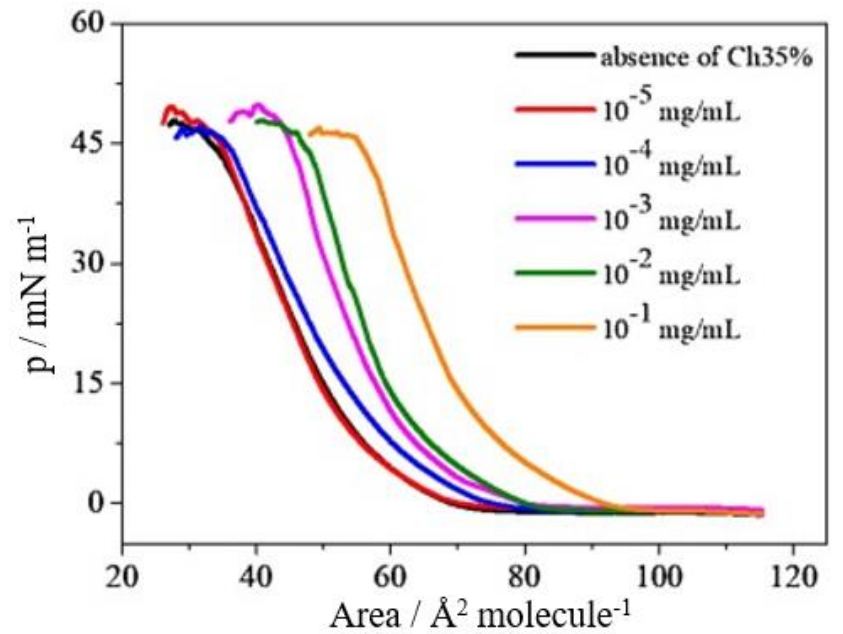

Figure 3. Surface pressure-area isotherms for monolayers of SM-DPPC-chol (1:1:1). Subphase: PBS ( $\mathrm{pH}$ 7.4) containing $\mathrm{Ch} 35 \%$ at different concentrations. Reproduced from Pereira et al. ${ }^{85}$ with Elsevier permission.

\section{Final Remarks}

The mimicking of cell membranes is, today, one of the most noble uses for Langmuir monolayers. In spite of the simplifications in the modeling, these monolayers are useful to obtain molecular-level information, which is virtually impossible with any other method. One may, for instance, identify the reasons why a peptide is effective against grampositive bacteria, but not for gram-negative bacteria by simply verifying that the peptide cannot disrupt a Langmuir monolayer of lipopolysaccharide ${ }^{51}$. With the in situ vibrational spectroscopy techniques, on the other hand, it is possible to determine the chemical groups involved in the interactions between biologically-relevant molecules and the model membranes. While recent achievements in modeling are promising, some of which were discussed in this review paper, there are important challenges to move the field forward. In our view, the two most relevant hurdles are the need to use more complex mixtures of lipids and other compounds to better mimic a real cell membrane and the need to understand the molecularlevel interactions based on theoretical models. The latter has been addressed with molecular dynamics simulations ${ }^{86}$, but the results are still limited, owing to computational resources and to phenomena involving charge transfer that is difficult to simulate with classical methods.

\section{Acknowledgments}

The authors gratefully acknowledge the financial support from CNPq and FAPESP (project number 2018/22214-6) and the post-doctoral fellowship of A. R. Pereira (2018/00878-0).

\section{References}

[1] Giner-Casares, J. J., Brezesinski, G., Möhwald, H., Langmuir monolayers as unique physical models, Current Opinion in Colloid \& Interface Science 19 (3) (2014) 176182. https://doi.org/10.1016/j.cocis.2013.07.006.

[2] Stefaniu, C., Brezesinski, G., Möhwald, H., Langmuir monolayers as models to study processes at membrane surfaces, Advances in Colloid and Interface Science 208 (2014) 197-213. https://doi.org/10.1016/j.cis.2014.02.013.

[3] Dynarowicz-Łatka, P., Dhanabalan, A., Oliveira Junior, O. N., Modern physicochemical research on Langmuir monolayers, Advances in Colloid and Interface Science 91 (2) 221-293. https://doi.org/10.1016/S00018686(99)00034-2.

[4] Yeagle, P., The membrane of cells, Academic Press, San Diego, 1993.

[5] Petty, H. R., Molecular biology of membranes: structure and function, Springer, Boston, 1993. https://doi.org/10.1007/978-1-4899-1146-9.

[6] RAYLEIGH, Surface tension, Nature 43 (1891) 437-439. https://doi.org/10.1038/043437c0.

[7] Langmuir, I., The constitution and fundamental properties of solids and liquids. II. Liquids., Journal of the American Chemical Society 39 (9) (1917) 1848-1906. https://doi.org/10.1021/ja02254a006.

[8] Nandi, N., Vollhardt, D., Chiral discrimination and recognition in Langmuir monolayers, Current Opinion in Colloid \& Interface Science, 13 (1-2) (2008) 40-46. https://doi.org/10.1016/j.cocis.2007.07.016.

[9] Blodgett, K. B., Langmuir, I., Built-Up Films of Barium Stearate and Their Optical Properties, Physical Review 51 (1937) 964-982. https://doi.org/10.1103/PhysRev.51.964. 
[10] Möbius, D., Kuhn, H., Monolayer assemblies of dyes to study the role of thermal collisions in energy-transfer, Israel Journal of Chemistry 18 (3-4) (1979) 375-384. https://doi.org/10.1002/ijch.197900058.

[11] Phan, M. D., Shin, K., A Langmuir Monolayer: Ideal Model Membrane to Study Cell, Journal of Chemical and Biological Interfaces 2 (1) (2014) 1-5. https://doi.org/10.1166/jcbi.2014.1028.

[12] Brockman, H., Lipid monolayers: why use half a membrane to characterize protein-membrane interactions? Current Opinion in Structural Biology 9 (4) (1999) 438-443. https://doi.org/10.1016/S0959-440X(99)80061-X.

[13] Nobre, T. M., Pavinatto, F. J., Caseli, L., BarrosTimmons, A., Dynarowicz-Łatka, P., Oliveira Junior, O. N., Interactions of bioactive molecules \& nanomaterials with Langmuir monolayers as cell membrane models, Thin Solid Films $\quad 593 \quad$ (2015) 158-188. https://doi.org/10.1016/j.tsf.2015.09.047.

[14] Ferreira, M., Caetano, W., Itri, R., Tabak, M., Oliveira Junior, O. N., Técnicas de caracterização para investigar interações no nível moleculas em filmes de Langmuir e Langmuir-Blodgett (LB), Química Nova 28 (3) (2005) 502510. https://doi.org/10.1590/S0100-40422005000300024.

[15] Petty, M. C., Langmuir-blodgett films: an introduction, Cambrigde University Express, Cambridge, 1996. https://doi.org/10.1017/CBO9780511622519.

[16] Stenhagen, E., Determination of organic structures by physical methods, Academic Press, New York, 1955.

[17] Wydro, P., Krajewska, B., Hạc-Wydro, K., Chitosan as a Lipid Binder: A Langmuir Monolayer Study of ChitosanLipid Interactions, Biomacromolecules 8 (2007) 2611-2617. https://doi.org/10.1021/bm700453x.

[18] Demchak, R. J., Fort Junior, T., Surface dipole moments of close-packed monolayers at the air-water interface, Journal of Colloid and Interface Science 46 (1974) 191-202. https://doi.org/10.1016/0021-9797(74)90002-2.

[19] Loschek, R., Mobius, D., Metalation of porphyrins in lipid monolayers at the air-water interface, Chemical Physics Letters $\quad 151 \quad(1-2) \quad$ (1988) 176-182. https://doi.org/10.1016/0009-2614(88)80091-5.

[20] Rice, P. A., McConnell, H. M., Critical shape transitions of monolayer lipid domains, Proceedings of the National Academy of Sciences of the United States of $\begin{array}{lllll}\text { America } & 86 & \text { (17) } & \text { (1989) }\end{array}$ https://doi.org/10.1073/pnas.86.17.6445.

[21] Hénon, S., Meunier, J., Microscope at the Brewster angle: direct observation of first-order phase transitions in monolayers, Review of Scientific Instruments 62 (4) (1991) 936-939. https://doi.org/10.1063/1.1142032.

[22] Hönig, D., Möbius, D., Brewster angle microscopy of LB films on solid substrates, Chemical Physics Letters 195 (1992) 50-52. https://doi.org/10.1016/0009-2614(92)85909T.

[23] Hönig, D., Möbius, D., Direct visualisation of monolayers at the air-water interface by Brewster angle microscopy, The Journal of Physical Chemistry 95 (12) (1991) 4590-4592. https://doi.org/10.1021/j100165a003.

[24] Vollhardt, D., Brewster angle microscopy: A preferential method for mesoscopic characterization of monolayers at the air/water interface, Current Opinion in Colloid \& Interface Science 19 (3) (2014) 183-197. https://doi.org/10.1016/j.cocis.2014.02.001.

[25] Möbius, D., Light microscopy of organized monolayers, Current Opinion in Colloid \& Interface Science 1 (2) (1996) 250-256. https://doi.org/10.1016/S1359-0294(96)80012-4.

[26] Kaercher, T., Hönig, D., Möbius, D., Brewster angle microscopy: a new method of visualizing the spreading of Meibomian lipids, International Ophthalmology 17 (6) (1993) 341-348. https://doi.org/10.1007/BF00915741.

[27] Möbius, D., Morphology and structural characterization of organized monolayers by Brewster angle microscopy, Current Opinion in Colloid \& Interface Science 3 (2) (1998) 137-142. https://doi.org/10.1016/S1359-0294(98)80005-8.

[28] Dluhy, R. A., Stephens, S. M., Widayati, S., Williams, A. D., Vibrational spectroscopy of biophysical monolayers. Applications of IR and Raman spectroscopy to biomembrane model systems at interfaces, Spectrochimica Acta Part AMolecular and Biomolecular Spectroscopy 51 (8) (1995) 1413-1447. https://doi.org/10.1016/0584-8539(94)00241-X.

[29] Mann, J. A., Dynamics, structure, and function of interfacial regions, Langmuir 1 (1) (1985) 10-23. https://doi.org/10.1021/la00061a002.

[30] Blaudez, D., Turlet, J.-M., Dufourcq, J., Bard, D., Buffeteau, T., Desbat, B., Investigations at the air/water interface using polarization modulation IR spectroscopy, Journal of the Chemical Society-Faraday Transactions 92 (4) (1996) 525-530. https://doi.org/10.1039/FT9969200525.

[31] Blaudez, D., Castano, S., Desbat, B., PM-IRRAS at liquid interfaces. In: Biointerface Characterization by Advanced IR Spectroscopy, Pradier, C. M., Chabal, Y. J., ed., Elsevier: Oxford, 2011, Ch. 2. https://doi.org/10.1016/B978-0-444-53558-0.00002-3.

[32] Urakawa, A., Bürgi, T., Baiker, A., Modulation excitation PM-IRRAS: A new possibility for simultaneous monitoring of surface and gas species and surface properties, 
CHIMIA International Journal for Chemistry 60 (4) (2006) 231-233. https://doi.org/10.2533/000942906777674949.

[33] Hunt, J. H., Guyot-sionnest, P., Shen, Y. R., Observation of $\mathrm{C}-\mathrm{H}$ stretch vibrations of monolayers of molecules optical Sum-frequency generation, Chemical Physics Letters $133 \quad$ (3) (1987) 189-192. https://doi.org/10.1016/0009-2614(87)87049-5.

[34] Rasing, T., Shen, Y. R., Kim, M. W., Valint Junior, P., Bock, J., Orientation of surfactant molecules at a liquid-air interface measured by optical second-harmonic generation, Physical Review A 31 (1) (1985) 537-539. https://doi.org/10.1103/PhysRevA.31.537.

[35] Shen, Y. R., The principles of nonlinear optics, Wiley and Sons, Hoboken, 2003.

[36] Boyd, R. R., Nonlinear optics, Academic Press, San Diego, 2003.

[37] Sung, W., Kim, D., Shen, Y. R. Sum-frequency vibrational spectroscopic studies of Langmuir monolayers, Current Applied Physics 13 (4) (2013) 619-632. https://doi.org/10.1016/j.cap.2012.12.002.

[38] Miranda, P. B., Du, Q., Shen, Y. R., Interaction of water with a fatty acid Langmuir film, Chemical Physics Letters 286 (1-2) (1998) 1-8. https://doi.org/10.1016/S00092614(97)01476-0.

[39] Sung, W., Seok, S., Kim, D., Tian, C. S., Shen, Y. R., Sum-Frequency Spectroscopic Study of Langmuir Monolayers of Lipids Having Oppositely Charged Headgroups, Langmuir 26 (23) (2010) 18266-18272. https://doi.org/10.1021/la103129z.

[40] Miranda, P. B., Shen, Y. R., Liquid Interfaces: A Study by Sum-Frequency Vibrational Spectroscopy, Journal of Physical Chemistry B 103 (17) (1999) 3292-3307. https://doi.org/10.1021/jp9843757.

[41] Shultz, M. J., Baldelli, S., Schnitzer, C., Simonelli, D., Aqueous Solution/Air Interfaces Probed with Sum Frequency Generation spectroscopy, Journal of Physical Chemistry B $106 \quad$ (21) (2002) 5313-5324. https://doi.org/10.1021/jp014466v.

[42] Lambert, A. G., Davies, P. B., Neivandt, D. J., Implementing the theory of sum frequency generation vibrational spectroscopy: A tutorial review, Applied Spectroscopy Reviews 40 (2) (2005) 103-145. https://doi.org/10.1081/ASR-200038326.

[43] Adamson, A. W., Gast, A. P., Physical Chemistry of Surfaces, John Wiley and Sons, New York, 1999.

[44] Stefaniu, C., Brezesinski, G., Grazing incidence X-ray diffraction studies of condensed double-chain phospholipid monolayers formed at the soft air/water interface, Advances in Colloid and Interface Science 207 (2014) 265-279. https://doi.org/10.1016/j.cis.2014.01.005.

[45] Stefaniu, C., Brezesinski, G., X-ray investigation of monolayers formed at the soft air/water interface, Current Opinion in Colloid \& Interface Science 19 (3) (2014) 216227. https://doi.org/10.1016/j.cocis.2014.01.004.

[46] Shapovalov, V. L., Ryskin, M. E., Konovalov, O. V., Hermelink, A., Brezesinski, G., Elemental analysis within the electrical double layer using total reflection X-ray fluorescence technique, Journal of Physical Chemistry B 111 (15) (2007) 3927-3934. https://doi.org/10.1021/jp066894c.

[47] Fischer, H. C., Chan, W. C. W., Nanotoxicity: the growing need for in vivo study, Current Opinion in

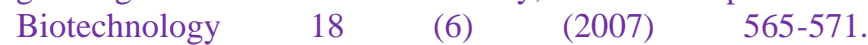
https://doi.org/10.1016/j.copbio.2007.11.008.

[48] Rodrigues, J. C., Caseli, L., Incorporation of bacitracin in Langmuir films of phospholipids at the air-water interface,

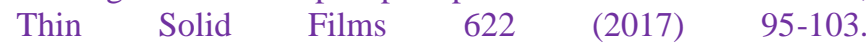
https://doi.org/10.1016/j.tsf.2016.12.019.

[49] Węder, K., Mach, M., Hac-Wydro, K., Wydro, P., Studies on the interactions of anticancer drug - Minerval with membrane lipids in binary and ternary Langmuir monolayers, Biochimica et Biophysica Acta (BBA) Biomembranes $\quad 1860 \quad$ (11) (2018) 2329-2336. https://doi.org/10.1016/j.bbamem.2018.05.019.

[50] Torgersen, M. L., Klokk, T. I., Kavaliauskiene, S., Klose, C., Simons, K., Skotland, T., Sandvig, K., The antitumor drug 2-hydroxyoleic acid (Minerval) stimulates signaling and retrograde transport, Oncotarget 7 (2016) 86871-86888. https://doi.org/10.18632/oncotarget.13508.

[51] Barbosa, S. C., Nobre, T. M., Volpati, D., Cilli, E. M., Correa, D. S., Oliveira Junior, O. N., The cyclic peptide labaditin does not alter the outer membrane integrity of Salmonella enterica serovar Typhimurium, Scientific Reports 9 (2019) 1993. https://doi.org/10.1038/s41598-01938551-5.

[52] Alvares, D. S., Viegas, T. G., Ruggiero Neto, J., Lipidpacking perturbation of model membranes by $\mathrm{pH}$-responsive antimicrobial peptides, Biophysical Reviews 9 (5) (2017) 669-682. https://doi.org/10.1007/s12551-017-0296-0.

[53] Girard-Egrot, A. P., Godoy, S., Blum, L. J., Enzyme association with lipidic Langmuir-Blodgett films: Interests and applications in nanobioscience, Advances in Colloid and Interface Science $116 \quad(1-3) \quad$ (2005) 205-225. https://doi.org/10.1016/j.cis.2005.04.006.

[54] Scholl, F. A., Caseli, L., Langmuir and LangmuirBlodgett films of lipids and penicillinase: Studies on adsorption and enzymatic activity, Colloids and Surfaces B: 
Biointerfaces 126 (2015) 232-236. https://doi.org/10.1016/j.colsurfb.2014.12.033.

[55] Araújo, F. T. de, Caseli, L., Rhodanese incorporated in Langmuir and Langmuir-Blodgett films of dimyristoylphosphatidic acid: Physical chemical properties and improvement of the enzyme activity, Colloids and Surfaces B: Biointerfaces $141 \quad$ (2016) 59-64. https://doi.org/10.1016/j.colsurfb.2016.01.037.

[56] Rocha Junior, C., Caseli, L., Adsorption and enzyme activity of asparaginase at lipid Langmuir and LangmuirBlodgett films, Materials Science \& Engineering: C 73 (2017) 579-584. https://doi.org/10.1016/j.msec.2016.12.041.

[57] Broome, J. D., L-asparaginase: discovery and development as a tumor-inhibitory agent, Cancer Treatment Reports 65 (Suppl. 4) (1981) 111-114.

[58] Makyla, K., Paluch, M., The linoleic acid influence on molecular interactions in the model of biological membrane, Colloids and Surfaces B: Biointerfaces 71 (1) (2009) 59-66. https://doi.org/10.1016/j.colsurfb.2009.01.005.

[59] Maximino, M. D., Constantino, C. J. L., Oliveira Junior, O. N., Alessio, P., Synergy in the interaction of amoxicillin and methylene blue with dipalmitoyl phosphatidyl choline (DPPC) monolayers, Applied Surface Science 476 (2019) 493-500. https://doi.org/10.1016/j.apsusc.2019.01.065.

[60] Tawfik, A. A., Noaman, I., El-Elsayyad, H., El-Mashad, N., Soliman, M., A study of the treatment of cutaneous fungal infection in animal model using photoactivated composite of methylene blue and gold nanoparticle, Photodiagnosis and Photodynamic Therapy 15 (2016) 59-69. https://doi.org/10.1016/j.pdpdt.2016.05.010.

[61] Zakaria, A., Hamdi, N., Abdel-Kader, R. M., Methylene Blue Improves Brain Mitochondrial ABAD Functions and Decreases $A \beta$ in a Neuroinflammatory Alzheimer's Disease Mouse Model, Molecular Neurobiology 53 (2) (2016) 12201228. https://doi.org/10.1007/s12035-014-9088-8.

[62] Broniatowski, M., Binczycka, M., Wójcik, A., Flasiński, M., Wydro, P., Polycyclic aromatic hydrocarbons in model bacterial membranes - Langmuir monolayer studies, Biochimica et Biophysica Acta (BBA) -

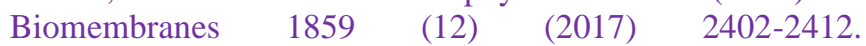
https://doi.org/10.1016/j.bbamem.2017.09.017.

[63] Purcaro, G., Moret, S., Conte, L. S., Overview on polycyclic aromatic hydrocarbons: Occurrence, legislation and innovative determination in foods, Talanta 105 (2013) 292-305. https://doi.org/10.1016/j.talanta.2012.10.041.

[64] Macrae, J. D., Hall, K. J., Comparison of methods used to determine the availability of polycyclic aromatic hydrocarbons in marine sediment, Environmental Science \& $\begin{array}{lllll}\text { Technology } & 32 & \text { (23) } & \text { (1998) }\end{array}$ https://doi.org/10.1021/es980165w.

[65] Kanaly, R. A., Harayama, S., Advances in the field of high-molecular-weight polycyclic aromatic hydrocarbon biodegradation by bacteria, Microbial Biotechnology 3 (2) (2010) 136-164. https://doi.org/10.1111/j.17517915.2009.00130.x.

[66] Korchowiec, B., Corvis, Y., Viitala, T., Feidt, C., Guiavarch, Y., Corbier, C., Rogalska, E., Interfacial Approach to Polyaromatic Hydrocarbon Toxicity: Phosphoglyceride and Cholesterol Monolayer Response to Phenantrene, Anthracene, Pyrene, Chrysene, and Benzo[a]pyrene, Journal of Physical Chemistry B 112 (43) (2008) 13518-13531. https://doi.org/10.1021/jp804080h.

[67] Zhang, Z. Y., Hao, C. C., Liu, H. Y., Zhang, X. G., Sun, R. G., Cholesterol mediates spontaneous insertion of Lycium barbarum polysaccharides in biomembrane model, $\begin{array}{llll}\text { Adsorption } & 26 & \text { (6) } & \text { (2020) 855-862. }\end{array}$ https://doi.org/10.1007/s10450-019-00180-9.

[68] Ahn, M., Park, J. S., Chae, S., Kim, S., Moon, C., Hyun, J. W., Shin, T., Hepatoprotective effects of Lycium chinense Miller fruit and its constituent betaine in $\mathrm{CCl}_{4-}$ induced hepatic damage in rats, Acta Histochemica 116 (6) (2014) 1104-1112. https://doi.org/10.1016/j.acthis.2014.05.004.

[69] Wnętrzak, A., Makyła-Juzak, K., Chachaj-Brekiesz, A., Lipiec, E., Romeu, N. V., Dynarowicz-Latka, P., Cyclosporin A distribution in cholesterol-sphingomyelin artificial membranes modeled as Langmuir monolayers, Colloids and Surfaces B: Biointerfaces 166 (2018) 286-294. https://doi.org/10.1016/j.colsurfb.2018.03.031.

[70] Barenholz, Y., Cholesterol and other membrane active sterols: from membrane evolution to "rafts", Progress in Lipid Research $41 \quad$ (1) (2002) 1-5. https://doi.org/10.1016/S0163-7827(01)00016-9.

[71] Ohvo-Rekilä, H., Ramstedt, B., Leppimaki, P., Slotte, J. P., Cholesterol interactions with phospholipids in membranes, Progress in Lipid Research 41 (1) (2002) 66-97. https://doi.org/10.1016/S0163-7827(01)00020-0.

[72] Crane, J. M., Tamm, L. M., Role of cholesterol in the formation and nature of lipid rafts in planar and spherical model membranes, Biophysical Journal 86 (5) (2004) 29652979. https://doi.org/10.1016/S0006-3495(04)74347-7.

[73] Fan, J., Sammalkorpi, M., Haataja, M., Formation and regulation of lipid microdomains in cell membranes: Theory, modeling, and speculation, FEBS Letters 584 (9) (2010) 1678-1684. https://doi.org/10.1016/j.febslet.2009.10.051. 
[74] Leslie, M., Do lipid rafts exist? Science 334 (6059) (2011) 1046-1047. https://doi.org/10.1126/science.334.6059.1046-b.

[75] Giri, R. P., Chakrabarti, A., Mukhopadhyay, M. K., Cholesterol-Induced Structural Changes in Saturated Phospholipid Model Membranes Revealed through X-ray Scattering Technique, Journal of Physical Chemistry B 121 (16) (2017) 4081-4090. https://doi.org/10.1021/acs.jpcb.6b12587.

[76] Gupta, K. C., Kumar, M. N. V. R., An Overview on Chitin and Chitosan Applications with an Emphasis on Controlled Drug Release Formulations, Journal of Macromolecular Science, Part C 40 (4) (2000) 273-308. https://doi.org/10.1081/MC-100102399.

[77] Liu, H., Du, Y., Wang, X., Sun, L., Chitosan kills bacteria through cell membrane damage, International Journal of Food Microbiology 95 (2) (2004) 147-155. https://doi.org/10.1016/j.ijfoodmicro.2004.01.022.

[78] Pavinatto, A., Delezuk, J. A. M., Souza, A. L., Pavinatto, F. J., Volpati, D., Miranda, P. B., Campana-Filho, S. P., Oliveira Junior, O. N., Experimental evidence for the mode of action based on electrostaticand hydrophobic forces to explain interaction between chitosans and phospholipid Langmuir monolayers, Colloids and Surfaces B: Biointerfaces $\quad 145 \quad$ (2016) 201-207. https://doi.org/10.1016/j.colsurfb.2016.05.001.

[79] Younes, I., Sellimi, S., Rinaudo, M., Jellouli, K., Nasri, M. Influence of acetylation degree and molecular weight of homogeneous chitosans on antibacterial and antifungal activities, International Journal of Food Microbiology 185 (2014) 57-63. https://doi.org/10.1016/j.ijfoodmicro.2014.04.029.

[80] Mellegård, H., Strand, S. P., Christensen, B. E., Granum, P. E., Hardy, S. P., Antibacterial activity of chemically defined chitosans: Influence of molecular weight, degree of acetylation and test organism, International Journal of Food Microbiology 148 (1) (2011) 48-54. https://doi.org/10.1016/j.ijfoodmicro.2011.04.023.

[81] Krajewska, B., Wydro, P., Janczyk, A., Probing the Modes of Antibacterial Activity of Chitosan. Effects of $\mathrm{pH}$ and Molecular Weight on Chitosan Interactions with Membrane Lipids in Langmuir Films, Biomacromolecules 12 (11) (2011) 4144-4152. https://doi.org/10.1021/bm2012295.

[82] Badawy, M. E. I., Rabea, E. I., Taktak, N. E. M., Antimicrobial and inhibitory enzyme activity of N-(benzyl) and quaternary $\mathrm{N}$-(benzyl) chitosan derivatives on plant pathogens, Carbohydrate Polymers 111 (2014) 670-682. https://doi.org/10.1016/j.carbpol.2014.04.098.
[83] Pavinatto, A., Pavinatto, F. J., Delezuk, J. A. D., Nobre, T. M., Souza, A. L., Campana-Filho, S. P., Oliveira Junior, O. N., Low molecular-weight chitosans are stronger biomembrane model perturbants, Colloids and Surfaces B: Biointerfaces $\quad 104 \quad$ (2013) 48-53. https://doi.org/10.1016/j.colsurfb.2012.11.047.

[84] Fiamingo, A., Oliveira Junior, O. N., Campana-Filho, S. C., Tuning the properties of high molecular weight chitosans to develop full water solubility within a wide $\mathrm{pH}$ range, ChemRxiv (2020). Preprint. https://doi.org/10.26434/chemrxiv.11854293.v1.

[85] Pereira, A. R., Fiamingo, A., Pedro, R. O., CampanaFilho, S. P., Miranda, P. B., Oliveira Junior, O. N., Enhanced chitosan effects on cell membrane models made with lipid raft monolayers, Colloids and Surfaces B: Biointerfaces 193 (2020)

111017. https://doi.org/10.1016/j.colsurfb.2020.111017.

[86] Mendonca, C. M. N., Balogh, D. T., Barbosa, S. C., Sintra, T. E., Ventura, S. P. M., Martins, L. F. G., Morgado, P., Filipe, E. J. M., Coutinho, J. A. P., Oliveira Junior, O. N., Barros-Timmons, A., Understanding the interactions of imidazolium-based ionic liquids with cell membrane models, Physical Chemistry Chemical Physics 20 (47) (2018) 2976429777. https://doi.org/10.1039/C8CP05035J. 